\title{
MALDI-TOF and ESI-MS Analysis of Oligosaccharides Labeled with a New Multifunctional Oligosaccharide Tag
}

\author{
Joanne Hsu, Soo Jin Chang, and Andreas H. Franz \\ Department of Chemistry, University of the Pacific, Stockton, California, USA
}

\begin{abstract}
A new multifunctional oligosaccharide label with a $1^{\circ}$ amino-group was synthesized and characterized. The oligosaccharide label was introduced into several neutral oligosaccharides by reductive amination, and the derivatives were analyzed by matrix-assisted laser desorption/ionization (MALDI) time-of-flight (TOF) and by electrospray ionization (ESI) mass spectrometry. It was demonstrated that the labeling reaction was satisfactory, and that as little as 50 pmol of starting material could be efficiently labeled with minimal loss to side reactions. A mixture of high-mannose $\mathrm{N}$-glycans released from ribonuclease $\mathrm{B}$ was labeled. The label did not appear to interfere with structural characterization of the oligosaccharides by mass spectrometry. $\mathrm{N}$-quaternization of the labeled oligosaccharides resulted in significantly increased sensitivity of detection with as little as $100 \mathrm{fmol}$ on the probe detected. Deuterium coding of labeled oligosaccharide mixtures and relative abundance of mixture components was investigated. A protocol for the chromatographic separation of mixtures of labeled oligosaccharides by HPLC was developed and is reported here. (J Am Soc Mass Spectrom 2006, 17, 194-204) (c) 2006 American Society for Mass Spectrometry
\end{abstract}

$\Lambda$ $\mathrm{n}$ inherent difficulty in the analysis of oligosaccharides is the lack of chromophores or fluorophores for sensitive detection [1]. Separation of carbohydrate mixtures and purification of components from these mixtures pose additional challenges. All of these are areas of current research and offer room for improvement. Over several decades, chemical methods have been developed for the introduction of chromophoric small organic molecules into oligosaccharides, frequently by reductive amination in the presence of sodium cyanoborohydride.

Current fluorescent labeling techniques for carbohydrates described in the literature have achieved good efficiency [2, 3]. However, in most cases, the described methods address only one analytical problem at a time. For example methods are available for the introduction of UV-active or fluorescent tags into oligosaccharides and their detection at the femto- and attomolar level through ultraviolet (UV)-absorbance, laser-induced fluorescence (LIF), or mass spectrometry (MS) [4-8]. Other tags have been developed for fluorophore-assisted carbohydrate electrophoretic (FACE) or capillary electrophoretic (CE) separation of carbohydrate mixtures [9, 10]. However, these tags do not allow sample cleanup, for example through established biotin/avidin protocols, and would require another derivatization step.

Published online January 9, 2006

Address reprint requests to Dr. A. H. Franz, Department of Chemistry, University of the Pacific, 3601 Pacific Avenue, Stockton, CA 95211, USA. E-mail: afranz@pacific.edu
MS analysis can be used for sensitive quantification studies and relative "profiling" of the labeled species from two different sources. Isotope-coded affinity tags (ICATs) have been described in proteomics [11] and have been developed into a complementing technique for two-dimensional gel electrophoresis [12, 13]. However, commercially available ICAT reagents can only be introduced into cysteine-containing peptides. This limits the applicability of the technique to such peptides. The use of ICAT labels for oligosaccharide analysis has not been described in the literature, to the best of our knowledge.

The vast majority of common labeling reagents for OS is composed of aromatic amines [7, 14-18]. The labeling reaction is based upon reduction of the Schiff's base formed between the amine and the sugar aldehyde to yield the aminomethyl derivative. Biotinylated diaminopyridine (BAP) and two other related tags, 4-(biotinamido)phenylacetylhydrazine (BPH) and biotinyl-L-3-(2naphthyl)-alanylhydrazide (BNAH), have been reported [19-24]. These labels combine UV-activity and bioaffinity. Except for the hydrazides $\mathrm{BPH}$ and $\mathrm{BNAH}$, however, the amino group in all of the above labels is in direct resonance with the aromatic heterocycle. In the case of BAP, this was found to reduce the amino group's nucleophilicity necessary for efficient introduction into oligosaccharides that are more sterically hindered at the reducing end for example by core-fucosylation.

More recently, benzylamine with increased nucleophilicity has been used for derivatization of oligosaccharides. Exhaustive $\mathrm{N}$-quaternization of the labeled 
sugars with methyliodide introduced a sequestered positive charge at the nitrogen and gave enhanced mass spectrometric detectability [25]. In another publication, positional isomers of $\mathrm{N}$-quaternized benzylamine-labeled oligosaccharides were separated by CE [26]. In this paper, we report a new multifunctional primary amine tag that combines UV-activity and bioaffinity.

\section{Experimental}

All reagents were used without purification unless specified. Solvents were of HPLC grade. Chloroform $\left(\mathrm{CHCl}_{3}\right)$ was purified by simple distillation before use. $\mathrm{N}, \mathrm{N}$-dimethylformamide was dried by azeotropic distillation with toluene, followed by $24 \mathrm{~h}$ reflux with $\mathrm{CaH}_{2}$ in a nitrogen atmosphere and subsequent fractionated distillation in vacuo. Solvents were removed on a Rotovap apparatus (Buechi, Switzerland). Micro liter volumes of solvent were removed in a heated $\left(40^{\circ} \mathrm{C}\right)$ CentriVap (Labconco, Kansas City, MO) with spinning at reduced pressure (12 mTorr). Oligosaccharides were purchased from Calbiochem Biosciences, Inc. (La Jolla, CA). Ribonuclease B was purchased from Sigma (St. Louis, MO), and PNGase F was purchased from Calbiochem (San Diego, CA). Samples were desalted by solid-phase extraction (SPE) on porous graphitized carbon (PGC) cartridges (Thermo-Hypersil Keystone, Bellefonte, PA). The cartridges were washed $\left(60 \% \mathrm{MeCN}_{1} \mathrm{H}_{2} \mathrm{O}\right)$ before use.

All ESI mass spectra were recorded on a VARIAN 1200 LC triple-quad mass spectrometer in positive mode. Solutions of $\mathrm{c} \sim 10^{-5} \mathrm{M}$ were used in $\mathrm{MeOH} /$
$\mathrm{H}_{2} \mathrm{O}(1: 1)$ at $400 \mu \mathrm{L}$ total volume. The analyte solution was sprayed by continuous infusion from the tip of a capillary with pneumatic assist $\left(\mathrm{N}_{2}\right.$ sheath gas) at a flow rate of $10 \mu \mathrm{L} / \mathrm{min}$. Desolvation of the spray was accomplished at elevated temperature $\left(\vartheta=50{ }^{\circ} \mathrm{C}\right.$ API chamber, $\vartheta=120-150^{\circ} \mathrm{C}$ capillary). The instrument was operated at $\sim 5^{*} 10^{-6}$ torr with a mass window of $\mathrm{m} / \mathrm{z}$ $0-1500$. A full mass spectrum was acquired from which a single ion of interest was subsequently isolated for Collision-Induced Dissociation (CID) at an argon background pressure of $1.0-1.4^{*} 10^{-3}$ torr with an excitation amplitude of 20-30 $\mathrm{V}_{p-p}$. The interpretation of CID spectra was based on the carbohydrate fragmentation nomenclature proposed by Domon and Costello [27].

Matrix-assisted laser desorption/ionization (MALDI) time of flight (TOF) mass spectra were recorded on a Shimadzu/Kratos (Columbia, MD) AXIMA CFR mass spectrometer in reflectron mode. The samples were coprecipitated with 2,5-dihydroxy-benzoic acid (DHB, 5 $\mathrm{mg} / 100 \mu \mathrm{l}$ in $\mathrm{MeCN} / \mathrm{H}_{2} \mathrm{O}$ 1:1) and were irradiated by a $\mathrm{N}_{2}$-laser $(\lambda=335 \mathrm{~nm})$ unless stated otherwise.

HPLC separation was carried out with a $\mathrm{C}_{18}$-column (Dionex Corp., Austin, TX) on a Shimadzu LC 10AT VP chromatograph with binary solvent delivery system and photodiode array detector (SPD M10A $V P, \lambda=215,254$, $280 \mathrm{~nm}$ ). The solvents used were $\mathrm{A}: \mathrm{H}_{2} \mathrm{O}$ and $\mathrm{B}: 60 \%$ $\mathrm{MeCN}$. The following solvent gradient was used: $50 \% \mathrm{~B}$ to $80 \%$ B over $10 \mathrm{~min}$ and additional $20 \mathrm{~min}$ isocratic for a total of $30 \mathrm{~min}$. The following flow rate gradient was used: $0.5 \mathrm{~mL} / \mathrm{min}$ to $1.0 \mathrm{~mL} / \mathrm{min}$ over $10 \mathrm{~min}$ and constant for the rest of the run. Fractions were collected with an ISCO Foxy fraction collector (Teledyne Isco, Lincoln, NE) at a rate of $1 \mathrm{~min} /$ tube.

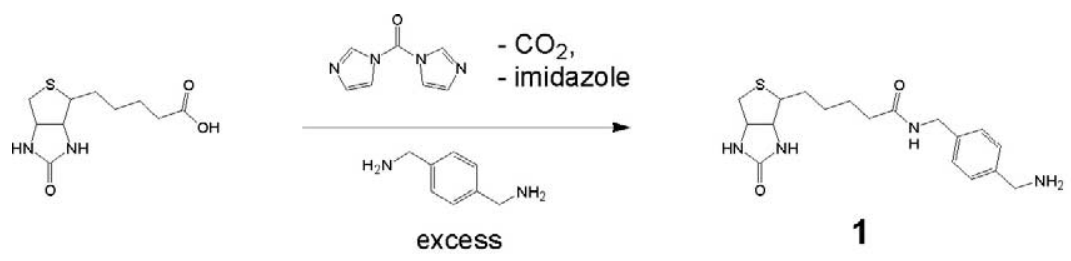

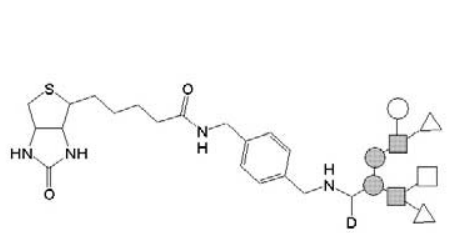

3

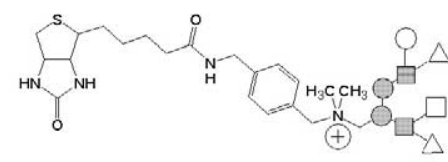

4
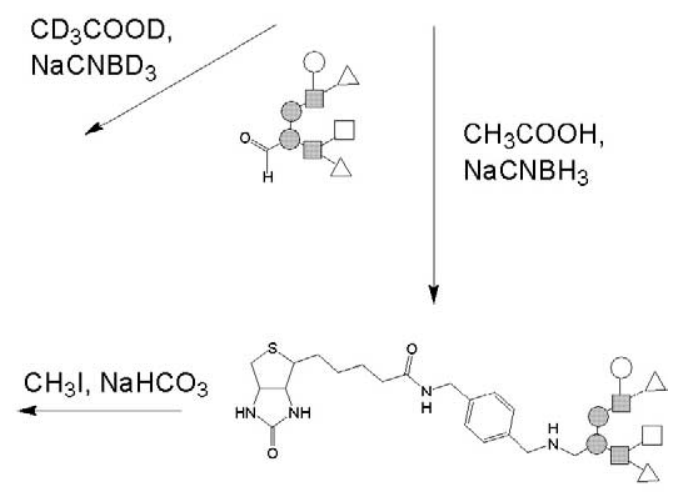

2

Scheme 1. Synthesis of Compound 1 and labeling of oligosaccharides with and without deuteriumcoding and N-quaternization. 


\section{5-(2-Oxo-Hexahydro-Thieno[3,4-d]Imidazol-4-yl)- Pentanoic Acid 4-Aminomethyl-Benzylamide (1)}

(+) Biotin (200 mg, $0.82 \mathrm{mmol}$, Scheme 1) was dissolved in dry DMF (5.0 mL). 1,1-carbonyldiimidazole (200 mg, 1.5 $\mathrm{mmol}$ ) was added at room-temperature. The solution was heated and stirred in an oil bath at $60^{\circ} \mathrm{C}$ for $0.5 \mathrm{~h}$ [28]. In a separate flask, xylylenediamine $(910 \mathrm{mg}, 8 \mathrm{~mol}$ equiv.) was dissolved in dry DMF $(5.0 \mathrm{~mL})$. At $0{ }^{\circ} \mathrm{C}$, small portions of the biotin solution were added to the $x y-$ lylenediamine solution ( $1 \mathrm{~mL}$ every $10 \mathrm{~min}$ for $1 \mathrm{~h}$ ) and stirring was continued at room-temperature (rt) overnight. The solids were removed by vacuum filtration (Hirsh funnel, water aspirator). The filtrate was transferred into a round-bottom flask and DMF was removed in vacuo (Rotovap, vacuum pump). The remainder was treated with $25 \mathrm{~mL} \mathrm{CHCl}_{3}$ at reflux for $0.5 \mathrm{~h}$. After the solution was cooled to rt, the solids were filtered off and washed three times, consecutively, with $10 \mathrm{~mL} \mathrm{CHCl}$ each. The crystals (pale yellow) were transferred into a glass vial and dried in vacuo; $\mathrm{mp} 147-148{ }^{\circ} \mathrm{C},{ }^{1} \mathrm{H}-\mathrm{NMR}$ (DMSO- $d_{6}, \delta$ in ppm): $\delta 1.35\left(\mathrm{~m}, 2 \mathrm{H}, \mathrm{CH}_{2}\right), \delta 1.45-1.67(\mathrm{~m}$, $\left.4 \mathrm{H}, \mathrm{CH}_{2}\right), \delta 1.87\left(\mathrm{~d}\right.$, broad, $\left.1 \mathrm{H}, \mathrm{CH}_{2} \mathrm{~N}^{\mathrm{Xyl}}\right), \delta 1.96(\mathrm{~d}$, broad, $\left.1 \mathrm{H}, \mathrm{CH}_{2} \mathrm{~N}^{\mathrm{Xyl}}\right), \delta 2.06\left(\mathrm{~m}\right.$, subm., $1 \mathrm{H}, \mathrm{CH}_{2} \mathrm{~N}^{\mathrm{Xyl}}$, amide) $\delta$ $2.14\left(\mathrm{t}, 2 \mathrm{H},{ }^{3} J_{\mathrm{CH} 2, \mathrm{CH} 2} 7.2, \mathrm{CH}_{2} \mathrm{CO}\right), \delta 2.59\left(\mathrm{~d}, 1 \mathrm{H},{ }^{2} J_{\mathrm{H} 3 \mathrm{~b}, \mathrm{H} 3 \mathrm{a}}\right.$ $\left.12.3,{ }^{3} J_{\mathrm{H} 3 \mathrm{~b}, \mathrm{H} 8}<1, \mathrm{H}-3 \mathrm{~b}\right), \delta 2.83\left(\mathrm{dd}, 1 \mathrm{H},{ }^{2} J_{\mathrm{H} 3 \mathrm{a}, \mathrm{H} 3 \mathrm{~b}} 12.3\right.$, $\left.{ }^{3} J_{\mathrm{H} 3 \mathrm{a}, \mathrm{H} 8} 5.1, \mathrm{H}-3 \mathrm{a}\right), \delta 3.10$ (ddd $\sim \mathrm{t}, 1 \mathrm{H},{ }^{3} \mathrm{~J}_{\mathrm{H} 1, \mathrm{H} 7} 8.1,{ }^{3} J_{\mathrm{H} 1, \mathrm{CH} 2}$ $6.3, \mathrm{H}-1), \delta 4.12\left(\mathrm{ddd}, 1 \mathrm{H},{ }^{3} J_{\mathrm{H}, \mathrm{H} 1} 7.5,{ }^{3} J_{\mathrm{H} 7, \mathrm{H} 8} 4.5,{ }^{3} J_{\mathrm{H} 7, \mathrm{NH}} 1.8\right.$, $\mathrm{H}-7), \delta 4.23\left(\mathrm{~d}, 2 \mathrm{H},{ }^{3} J_{\mathrm{CH} 2, \mathrm{NH}} 5.7, \mathrm{CH}_{2} \mathrm{~N}^{\mathrm{Xyl}}\right.$, amide), $\delta 4.30$ (ddd $\sim \mathrm{t}, 1 \mathrm{H},{ }^{3} J_{\mathrm{H} 8, \mathrm{H} 7}$ not resolved, $\left.{ }^{3} J_{\mathrm{H} 8, \mathrm{H} 3 \mathrm{a}} 6.3, \mathrm{H}-8\right), \delta 6.33$ (s, broad, $1 \mathrm{H}, \mathrm{NH}$, urea), $\delta 6.40$ (s, broad, $1 \mathrm{H}, \mathrm{NH}$, urea), $\delta$ 7.1-7.3 (m, AB-mixing, $\left.4 \mathrm{H}, \mathrm{H}^{\text {arom. }}\right), \delta 8.23\left(\mathrm{t}, 1 \mathrm{H},{ }^{3} J_{\mathrm{NH}, \mathrm{CH} 2}\right.$ 6.0, NH, amide); ${ }^{13} \mathrm{C}-\mathrm{NMR}$ (DMSO- $d_{6}, \delta$ in ppm): d 1.40, 26.79, 29.50, 29.70, 36.62, 43.22, 55.57, 56.83, 60.51, 62.34, $62.44,128.31\left(C^{\text {arom }}\right), 128.41\left(C^{\text {arom }}\right), 128.73\left(C^{\text {arom }}\right), 128.85$ $\left(\mathrm{C}^{\text {arom }}\right), 138.90$ ( $\left.\mathrm{C}^{\text {arom,quat. }}\right), 140.58$ ( $\left.\mathrm{C}^{\text {arom,quat }}\right), 173.13$ (RCONHR), 207.70 (RNHCONHR); $\mathrm{C}_{18} \mathrm{H}_{26} \mathrm{~N}_{4} \mathrm{O}_{2} \mathrm{~S}$ theor: $362.18 \mathrm{u}$; found: High-resolution MS [M + $\mathrm{H}]^{+} \mathrm{m} / \mathrm{z} 363.31$.

\section{General Procedure for Labeling of Mono- and Oligosaccharides with $\mathbf{1}$}

The oligosaccharide was dissolved in $200 \mu \mathrm{L}$ of methanol to a final concentration of $\sim 10^{-4} \mathrm{M}$ in a plastic microcentrifuge vial with lid (Scheme 1). Compound 1 (0.1 $\mathrm{mg}$ from a stock solution) was added followed by glacial acetic acid $(1 \mu \mathrm{L})$ and $\mathrm{NaCNBH}_{3}(\sim 10 \mathrm{mg})$. The vial was sealed and heated at $70^{\circ} \mathrm{C}$ for 2 to $3 \mathrm{~h}$. Subsequently, the solvent was removed in vacuo in a CentriVap. The residue was dissolved in $200 \mu \mathrm{L}$ of deionized water. A Porous Graphitized Carbon (PGC) cartridge was washed and equilibrated with $60 \% \mathrm{MeCN}$ $(2 \times 1 \mathrm{~mL})$ followed by deionized water $(2 \times 1 \mathrm{~mL})$. The aqueous solution of the labeled oligosaccharide was transferred into the PGC cartridge and was washed slowly with deionized water $(3 \times 1 \mathrm{~mL})$ to remove salts. The desalted sample was eluted off the cartridge with $60 \% \mathrm{MeCN}$. Three $0.5 \mathrm{~mL}$ fractions of the eluent were collected in microcentrifuge vials. These samples were directly subjected to mass spectrometric analysis. For prolonged storage, the solvent was removed in vacuo. The monosaccharides $D$-glucose, $D$-galactose, $D$-mannose, $\mathrm{N}$-acetyl- $D$-glucosamine, and $L$-fucose and the oligosaccharides maltotriose, maltohexaose, LNF-II, and LNDFH-II were labeled.

Deuterium-coding. The general procedure was followed, and $\mathrm{NaCNBD}_{3}$ was substituted for $\mathrm{NaCNBH}_{3}$ (Scheme 1).

\section{General Method for N-Quaternization of Derivatives Labeled with $\mathbf{1}$}

The oligosaccharide derivative obtained by the general labeling method (vide supra) was dissolved in methanol $\left(400 \mu \mathrm{L}\right.$, Scheme 1). MeI $(5 \mu \mathrm{L})$ and $\mathrm{NaHCO}_{3}(\sim 1$ $\mathrm{mg}$ ) were added and the solution was warmed in an oil bath to $40{ }^{\circ} \mathrm{C}$ overnight. Aliquots $(50 \mu \mathrm{L})$ were taken after $15 \mathrm{~min}, 1 \mathrm{~h}, 2 \mathrm{~h}, 12 \mathrm{~h}$, and $24 \mathrm{~h}$. The solvent was immediately removed in vacuo to stop the quaternization reaction. Each sample was dissolved in deionized water $(200 \mu \mathrm{L})$ and was desalted (PCG cartridge). The fractions collected were evaporated and redissolved in $\mathrm{MeOH} / \mathrm{H}_{2} \mathrm{O}(1: 1,400 \mu \mathrm{L})$ for mass spectrometric analysis. A reaction period of $2 \mathrm{~h}$ was found sufficient for complete quaternization.

$\mathrm{N}$-Quaternization of lacto-N-difucohexaose (LNDFH II). LNDFH II $(10 \mu \mathrm{g})$ was labeled with tag $\mathbf{1}$ according to the general procedure. The desalted fractions from the PGC cartridge were combined, dried, and subsequently dissolved in $50 \mu \mathrm{l}$ of $\mathrm{MeOH} / \mathrm{H}_{2} \mathrm{O}(1: 1)$. MeI $(2 \mu \mathrm{L})$ was added, followed by $1 \mathrm{mg}$ of $\mathrm{NaHCO}_{3}$, and the reaction was kept at room-temperature for $2 \mathrm{~h}$. To terminate the quaternization reaction, the solvent was removed in vacuo. Subsequently, the sample was dissolved in $\mathrm{H}_{2} \mathrm{O}$ and was desalted by PGC cartridge, followed by mass spectrometric analysis.

\section{Limit of Labeling Small Oligosaccharide Quantities}

An aqueous solution of maltotriose (c $=1 \mathrm{mg} / \mathrm{mL}$ ) was diluted to $10^{-7} \mathrm{M}$ final concentration. Various aliquots of the stock solution $\left(500 \mu \mathrm{L}, 5.8 \times 10^{-8} \mathrm{~g}, 50 \mathrm{pmol}\right.$ sugar; $200 \mu \mathrm{L}, 2.3 \times 10^{-8} \mathrm{~g}$, 20 pmol sugar; $100 \mu \mathrm{L}, 1.1$ $\times 10^{-8} \mathrm{~g}, 10$ pmol sugar; $50 \mu \mathrm{L}, 5.0 \times 10^{-9} \mathrm{~g}, 5 \mathrm{pmol}$ sugar; $10 \mu \mathrm{L}, 1.0 \times 10^{-9} \mathrm{~g}, 1$ pmol sugar) were labeled according to the general procedure. The solvent was removed in vacuo and the maltotriose samples were labeled as described in the general procedure. The lower detection limit of the derivatives was determined by MALDI mass spectrometry.

\section{Release of N-Glycans from Ribonuclease B}

Previously published methods for the release of $N$ linked glycans from glycoproteins were used [29, 30]. 

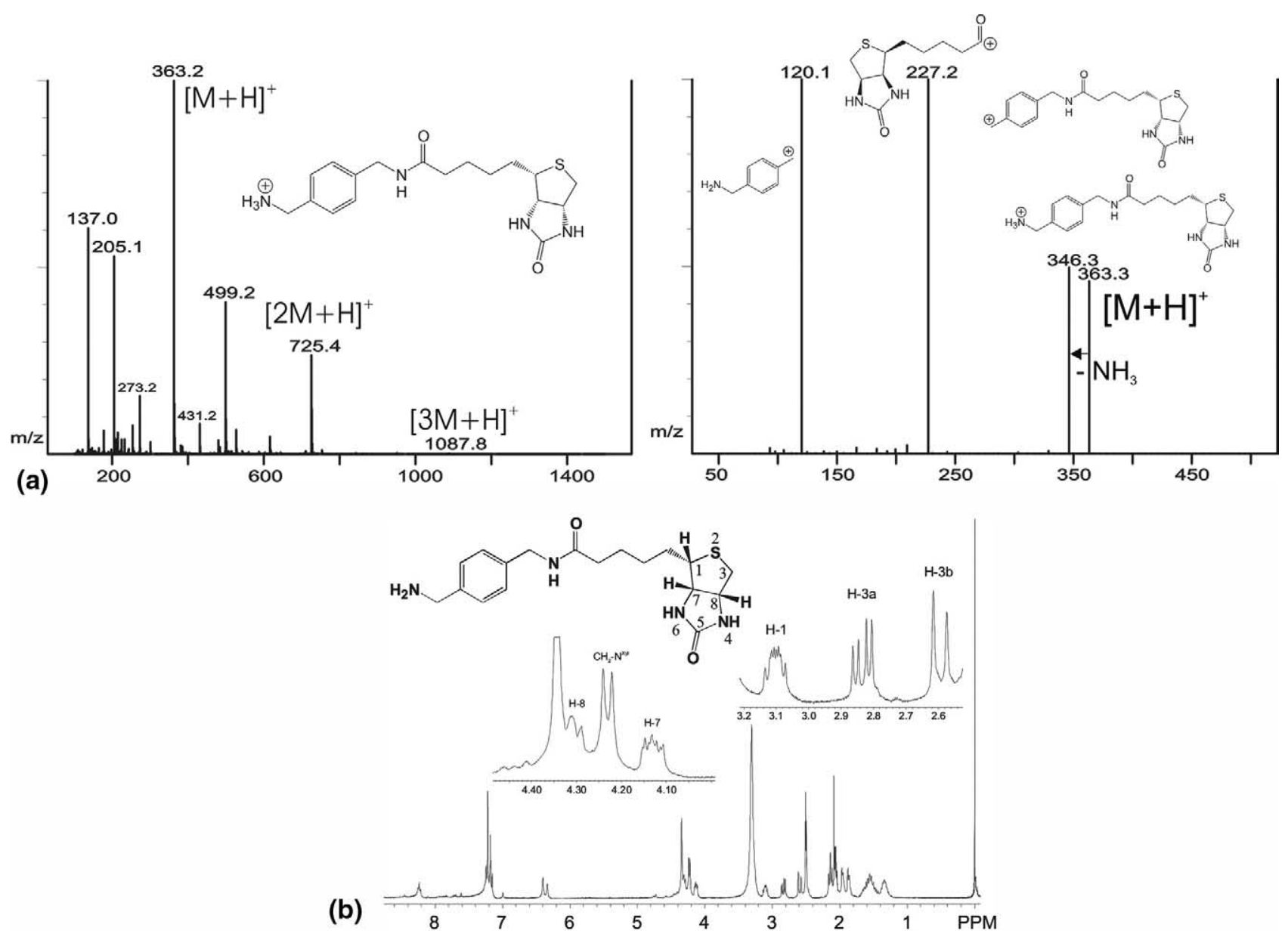

Figure 1. (a left): ESI-MS spectrum of Compound 1. The formation of proton-bound non-covalent dimer- and trimer-complexes is apparent; (a right): ESI-CID-spectrum of $[\mathbf{1}+\mathrm{H}]^{+}$. (b) NMR spectrum of $\mathbf{1}$ and proton assignment.

Ribonuclease B ( $3 \mathrm{mg})$ was denatured ( $2 \%$ aq. SDS, $90{ }^{\circ} \mathrm{C}$ for $10 \mathrm{~min}$ ), and the solution was cooled to rt. A solution of $\mathrm{NaHPO}_{4}(50 \mathrm{mM}, \mathrm{pH} 7.5,100 \mu \mathrm{L})$ was added to maintain the $7.5 \mathrm{pH}$-optimum for the enzyme. PNGase F ( $1 \mu \mathrm{L}, \sim 5$ units) in Tris-HCl-buffer $(20 \mathrm{mM})$ and EDTA $(1 \mathrm{mM})$ was added, and the solution was incubated at $37^{\circ} \mathrm{C}$ for $12 \mathrm{~h}$.

\section{HPLC Separation of Mixtures of Labeled Oligosaccharides}

A mixture of standard oligosaccharides was subjected to the labeling procedure. The typical absolute amount of the components was $1 \mathrm{nmol}$ taken from an aqueous stock solution with a concentration of $1 \mu \mathrm{mol} / \mathrm{mL}$. The general workup procedure for labeled oligosaccharides was followed, and the residue was dissolved $(60 \%$ aqueous $\mathrm{MeCN}$ ) to a final volume of $100 \mu \mathrm{L}$. Single injections of $20 \mathrm{~mL}$ were separated, and the collected fractions were concentrated. The identity of the separated compounds was confirmed by MALDI-TOF MS analysis.

\section{Results and Discussion}

\section{Synthesis of the Label}

The synthesis of the new oligosaccharide tag $\mathbf{1}$ and subsequent labeling reactions are shown in Scheme $\mathbf{1}$. Biotin was activated by 1,1'-carbonyl diimidazole. Nucleophilic attack of the electrophilic carbonyl group by the aminomethyl groups of xylylenediamine gave the coupled product. To minimize the extent of double substitution, the biotin solution was added to an excess of xylylenediamine (inverse addition) to prevent high concentration of biotin. Dry DMF was used in the synthesis because the presence of water and amines would destroy the activated biotin and would lead to an overall low yield of coupling product.

The structure of $\mathbf{1}$ was confirmed by mass spectrometry, and both ${ }^{1} \mathrm{H}-\mathrm{NMR}$ and ${ }^{13} \mathrm{C}-\mathrm{NMR}$. Electrospray ionization (ESI) MS analysis of $\mathbf{1}$ yielded a strong [M + $\mathrm{H}]^{+}$signal at $m / z 363.2$ (Figure 1a, left). The compound displayed a significant tendency to form a protonbound dimer $[2 \mathrm{M}+\mathrm{H}]^{+}$(peak at $m / z 725.4$ ) and trace of 
a proton-bound trimer $[3 \mathrm{M}+\mathrm{H}]^{+}$(peak at $m / z$ 1087.6). The identity of the dimer was supported by a lowenergy collision-induced dissociation experiment (CID, data not shown). The isolated $[2 \mathrm{M}+\mathrm{H}]^{+}$ion at $\mathrm{m} / \mathrm{z}$ 725.4 was allowed to undergo collisional cooling with argon (no excitation) in the CID cell. It was observed that the isolated ion could be dissociated under these mild conditions to yield the protonated monomer $[\mathrm{M}+$ $\mathrm{H}^{+}$at $\mathrm{m} / \mathrm{z}$ 363.2. The ease of dissociation is consistent with a weak noncovalent interaction.

The ion at $m / z 363.2$ was subsequently isolated and fragmented by CID at low excitation energy (Figure 1a, right). The observed fragment ions were consistent with the proposed tag structure. Loss of an ammonia group $(\Delta \mathrm{m}=17 \mathrm{u})$ resulted in a peak at $m / z=346.3$ representing a benzylic cation with delocalized charge. The peak at $m / z 227.2$ was assigned to the acylium ion of the biotin component. Similarly, the peak $\mathrm{m} / \mathrm{z} 120.1$ corresponded to the benzylic cation of the xylylenediamine component.

The ${ }^{1} \mathrm{H}-\mathrm{NMR}$ spectrum of Compound $\mathbf{1}$ was fully consistent with its structure (Figure 1b). The spectrum displayed the hydrocarbon envelope of the biotin unit between 1.3-1.7 ppm and at $2.1 \mathrm{ppm}$. The protons of the bicyclic heterocycle were assigned based on ${ }^{1} \mathrm{H}-{ }^{1} \mathrm{H}-$ COSY correlations (data not shown). Proton $\mathrm{H}-1$ caused a signal at $3.1 \mathrm{ppm}$ with a ddd $\sim \mathrm{dt}$ multiplicity with one unresolved coupling. The two triplet values of 6.3 $\mathrm{Hz}$ are consistent with average coupling constants to the neighboring $\mathrm{CH}_{2}$ group (free rotation). The third $J$-value of $8.1 \mathrm{~Hz}$ represents the quasi syn-eclipsed coupling to H-7. The two protons $\mathrm{H}-3 \mathrm{a}$ and $\mathrm{H}-3 \mathrm{~b}$ were identified as signals at 2.83 (dd) and $2.59 \mathrm{ppm}(\mathrm{d})$, respectively. A large 2-bond geminal coupling constant of $12.3 \mathrm{~Hz}$ was observed. Whereas $\mathrm{H}-3 \mathrm{~b}$ did not display any additional coupling to the neighboring $\mathrm{H}-8\left(\sim 90^{\circ}\right.$ dihedral angle), $\mathrm{H}-3 \mathrm{a}$ displayed a ${ }^{3} J_{3 \mathrm{a}, 8} 5.1 \mathrm{~Hz}$ constant. The signal caused by H-8 was identified as submerged $\mathrm{ddd} \sim \mathrm{t}$ at $4.30 \mathrm{ppm}$ with a triplet constant of $6.3 \mathrm{~Hz}$ towards H-3a and H-7 (too large). A COSY cross-peak identified $\mathrm{H}-7$ at $4.12 \mathrm{ppm}$ with couplings of $1.8 \mathrm{~Hz}$ $(\rightarrow \mathrm{NH}), 4.5 \mathrm{~Hz}(\rightarrow \mathrm{H}-8)$, and $7.5 \mathrm{~Hz}(\rightarrow \mathrm{H}-1)$. The two urea NH-resonances at 6.33 and $6.40 \mathrm{ppm}$, respectively, did not display any resolved couplings. The xylylene diamine component of tag $\mathbf{1}$ gave an amide $\mathrm{NH}$ group signal at $8.23 \mathrm{ppm}$ with triplet coupling constants of 6.0 $\mathrm{Hz}$ towards the benzylic $\mathrm{CH}_{2}$-group. The two benzylic amide $\mathrm{CH}_{2}$-protons were observed at $4.23 \mathrm{ppm}$ and 2.06 ppm (submerged). The signal at $4.23 \mathrm{ppm}$ was split into a doublet of $5.7 \mathrm{~Hz}$ indicating free amide bond rotation. The two benzylic aminomethyl $\mathrm{CH}_{2}$-protons were observed at 1.87 and $1.96 \mathrm{ppm}$.

\section{Results of Mono- and Oligosaccharide Labeling}

We labeled a variety of monosaccharides with Compound 1, namely glucose (Glc), galactose $(\mathrm{Gal})$, mannose (Man), fucose (Fuc), and $\mathrm{N}$-acetylglucosamine (GlcNAc). In all cases, the label was introduced with high

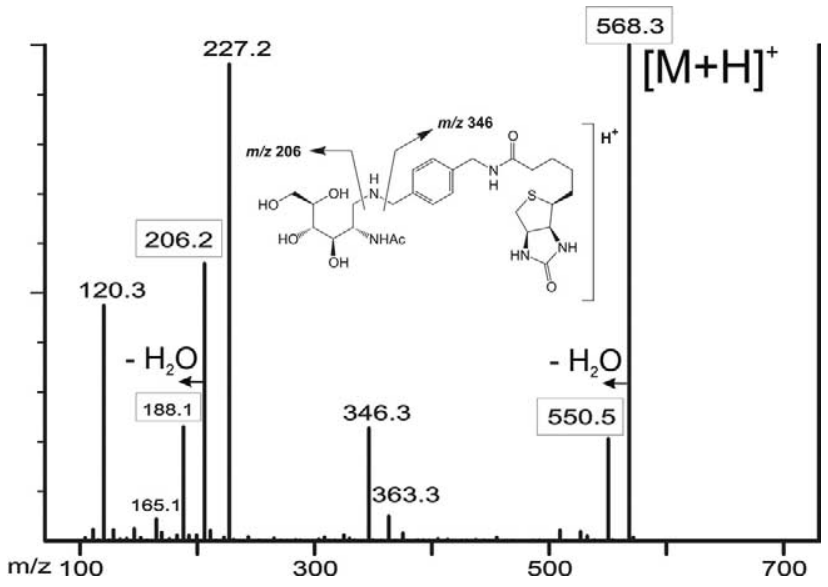

Figure 2. ESI-CID-spectrum of the isolated ion $[\mathrm{M}+\mathrm{H}]^{+}$for GlcNAc labeled with $\mathbf{1}$ at $\mathrm{m} / \mathrm{z}$ 568.3. The characteristic fragment ions of the tag and a pronounced tendency for water loss were observed.

efficiency, and no trace of the unlabeled alditol form of the sugar was detected by mass spectrometry after desalting. We were especially interested in GlcNAc because it is found as the reducing end of many naturally occurring oligosaccharides. The ESI CID mass spectrum of labeled GlcNAc is shown in Figure 2. Besides the label-specific fragment ions at $\mathrm{m} / \mathrm{z} 346.3$, 227.2, and 120.3, we observed the protonated molecule at $m / z 568.3$, a fragment ion $\left[\mathrm{M}-\mathrm{H}_{2} \mathrm{O}+\mathrm{H}\right]^{+}$at $m / z$ 550.5, and a GlcNAc fragment ion at $\mathrm{m} / \mathrm{z}$ 206.2.

The standard oligosaccharides lacto- $N$-difucohexaose 2 (LNDFH 2) and blood group A trisaccharide were labeled. In both cases, we did not observe any significant loss of labeling efficiency. From the MALDI and ESI mass spectra of the desalted samples, the efficiency was estimated at $>90 \%$. Both protonated molecules and sodiated species could be generated in excellent abundance. With MALDI, the former was obtained by laser desorption from a sample cocrystallized with DHB matrix alone; the latter was observed when the sample was doped with $1 \mu \mathrm{L}$ of a saturated methanolic $\mathrm{NaCl}$ solution. Figure 3 shows MALDI-PSD spectra of (Figure 3a) labeled A-trisaccharide and (Figure 3b) labeled LNDFH 2. The standard carbohydrate fragmentation nomenclature by Domon and Costello was used throughout this discussion [27]. Upon ion-gate isolation of the protonated molecule from labeled blood group A-trisaccharide at $\mathrm{m} / \mathrm{z}$ 867.7, excess energy deposited during laser desorption yielded the $Y_{1 \beta}(\mathrm{m} / \mathrm{z}$ 730.7), the $Y_{1 \alpha}\left(m / z\right.$ 673.5), and the $Y_{1 \alpha}+Y_{1 \beta}(m / z 527.3)$ combination fragment ions (Figure 3a). Unlike the frequently reported ease of fucose loss from an oligosaccharide during CID or PSD analysis along with high abundance of the corresponding fragment ion, we did not find such behavior with labeled A-trisaccharide. The abundance of the $\mathrm{Y}_{1 \alpha}$ (GlcNAc-loss) and the $\mathrm{Y}_{1 \beta}$ (Fuc-loss) ion was almost identical.

The labeled derivative of LNDFH 2 gave similarly satisfactory structural information in both ESI and MALDI mass spectra. The MALDI-PSD spectrum of the 

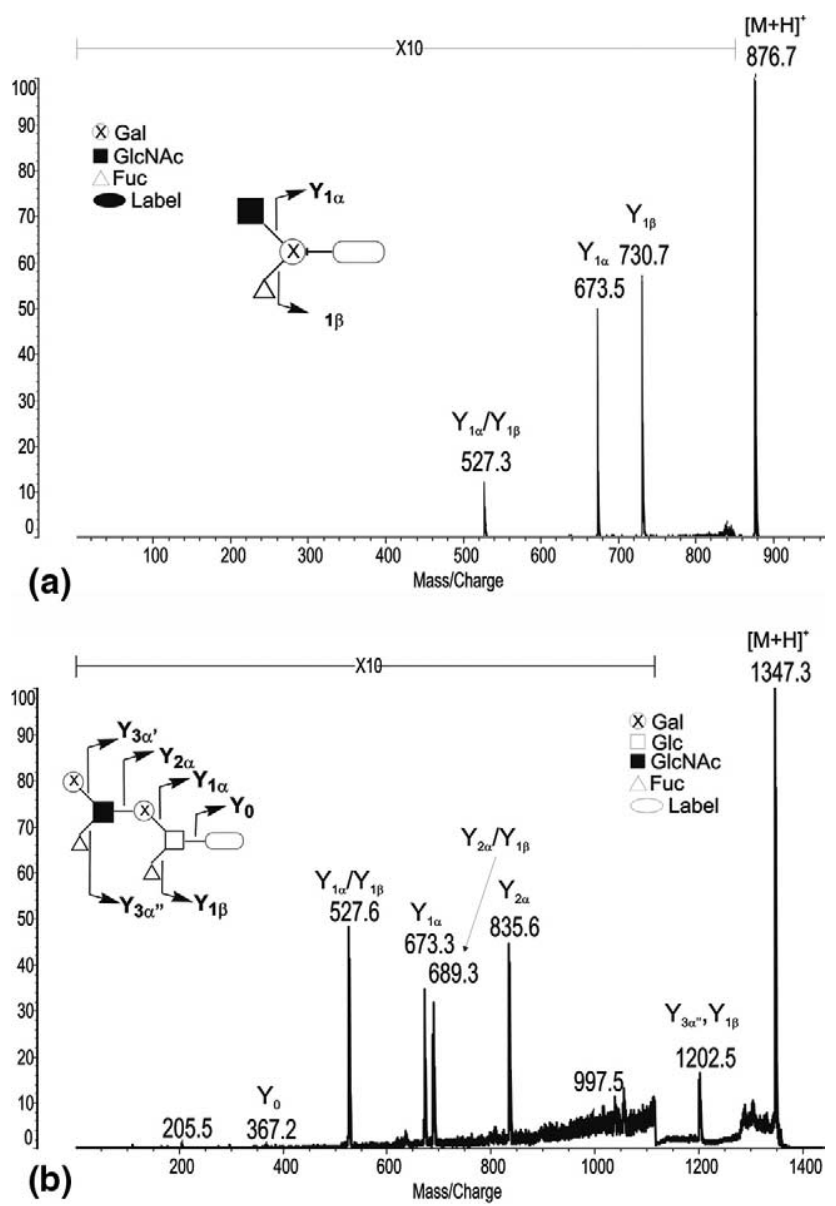

Figure 3. MALDI-TOF-PSD-spectrum of $[\mathrm{M}+\mathrm{H}]^{+}$of (a) blood group A-trisaccharide labeled with $\mathbf{1}$ and (b) LNDFH 2 labeled with 1.

ion-gated $[\mathrm{M}+\mathrm{H}]^{+}$at $m / z 1347.3$ is shown in Figure $3 b$. The loss of either fucose unit yielded indistinguishable $Y_{3 \alpha^{\prime \prime}}$ and $Y_{1 \beta}$ fragment ions at $\mathrm{m} / \mathrm{z} 1202.5$ in high abundance compared to all other fragment ions. The loss of the terminal galactose $\left(\mathrm{Y}_{3 \alpha^{\prime}}\right.$ ion) was not observed. However, the $Y_{2 \alpha}\left(m / z\right.$ 835.6), $Y_{1 \alpha}(m / z$ 673.3), and $Y_{0}(m / z$ 367.2) ion series was observed. Combination fragment ions $Y_{1 \alpha}+Y_{1 \beta}\left(m / z\right.$ 527.6) and $Y_{2 \alpha}+Y_{1 \beta}$ $(\mathrm{m} / \mathrm{z}$ 689.3) yielded information about the branching point in LNDFH 2 between the $\alpha$ - and $\beta$-chains. However, the absence of the loss of terminal galactose did not allow us to collect mass spectral evidence for the branching point between the $\alpha^{\prime}$ - and the $\alpha>30>$-chains.

For labeling reagents to be useful, it must be possible to introduce the tag into glycans isolated from glycoproteins. We chose ribonuclease B (RNase B) as a standard glycoprotein. The $N$-linked glycans were released by treating RNase B with peptide- $\mathrm{N}$-deglycanase $\mathrm{F}$ (PNGase F) [31-35] in phosphate-buffered solution ( $\mathrm{pH}$ 7.4) at $37^{\circ} \mathrm{C}$ overnight [29]. The identity of the glycans was established by MALDI-TOF MS (Figure 4a). The sodiated species of (Man $)_{n}(\mathrm{GlcNAc})_{2}$ with $n=5,6,7$, and 8 were observed at identical $\mathrm{m} / \mathrm{z}$ values as reported [3]. We subsequently labeled the glycans with the new tag and recorded a MALDI-TOF spectrum (Figure $4 b$ ). Only the $[\mathrm{M}+\mathrm{H}]^{+}$of labeled (Man) $)_{5}(\mathrm{GlcNAc})_{2}(\mathrm{~m} / \mathrm{z}$ 1582.4) and (Man $)_{6}(\mathrm{GlcNAc})_{2}(\mathrm{~m} / \mathrm{z}$ 1744.4) were observed. Both protonated molecules lost water readily as apparent by the respective peaks at $\mathrm{m} / \mathrm{z} 1564.3$ and 1726.4. This was analogous to the loss of water from [M $+\mathrm{H}]^{+}$of labeled GlcNAc observed before (Figure 2). Additional $[\mathrm{M}+\mathrm{Na}]^{+}$signals of the sugar alditols were observed at $\mathrm{m} / \mathrm{z} 1098.0,1260.2$, and 1422.2. The efficiency of the labeling reaction was estimated to be $50 \%$ under the conditions used.

\section{Isotope-Coding of Oligosaccharides}

When we replaced $\mathrm{NaCNBH}_{3}$ with $\mathrm{NaCNBD}_{3}$, the corresponding D-coded oligosaccharide derivatives were obtained. The deuterium code did not have any apparent effect on the fragmentation behavior of the compounds. All labeled oligosaccharides we investigated (e.g., maltohexaose, Figure 5a) displayed identical fragmentation behavior with or without isotope code as was expected.

For the determination of relative abundance of labeled sugars by isotope coding, an identical amount of

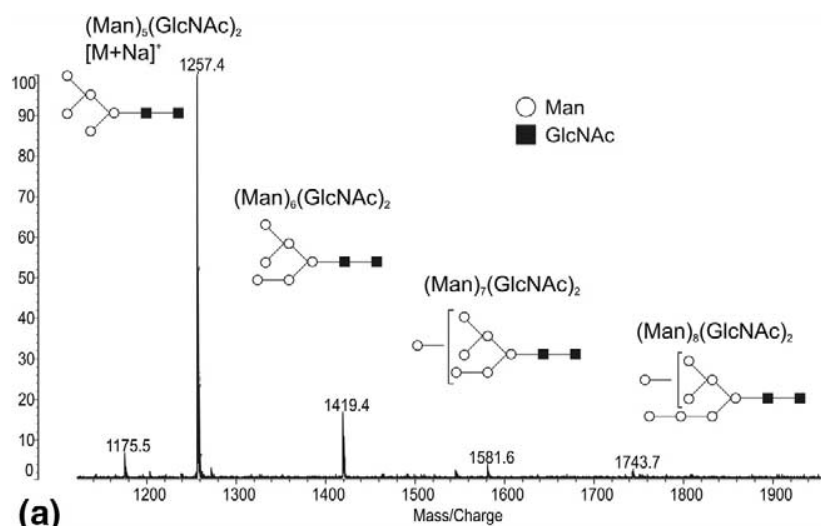

(a)

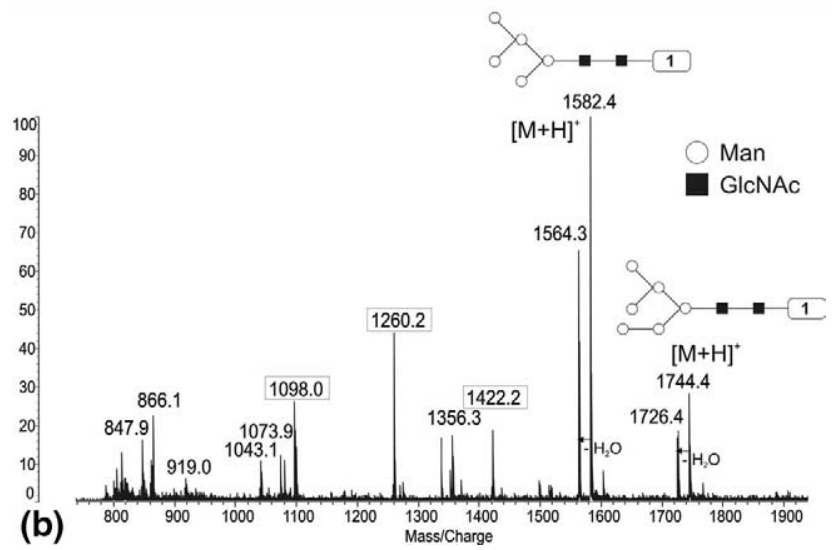

Figure 4. MALDI-TOF-Spectrum of (a) sodiated N-glycans released with PNGase F from RNAse B (1 mg protein, unknown final concentration of glycans in $50 \mu \mathrm{L} 60 \% \mathrm{MeCN}$ ) and (b) RNAse $\mathrm{N}$-glycans $[10 \mu \mathrm{L}$ from (a)] labeled with 1. A loss of labeling efficiency was indicated by the presence of sodiated sugar alditols (boxed $\mathrm{m} / \mathrm{z}$ values). 
(a)
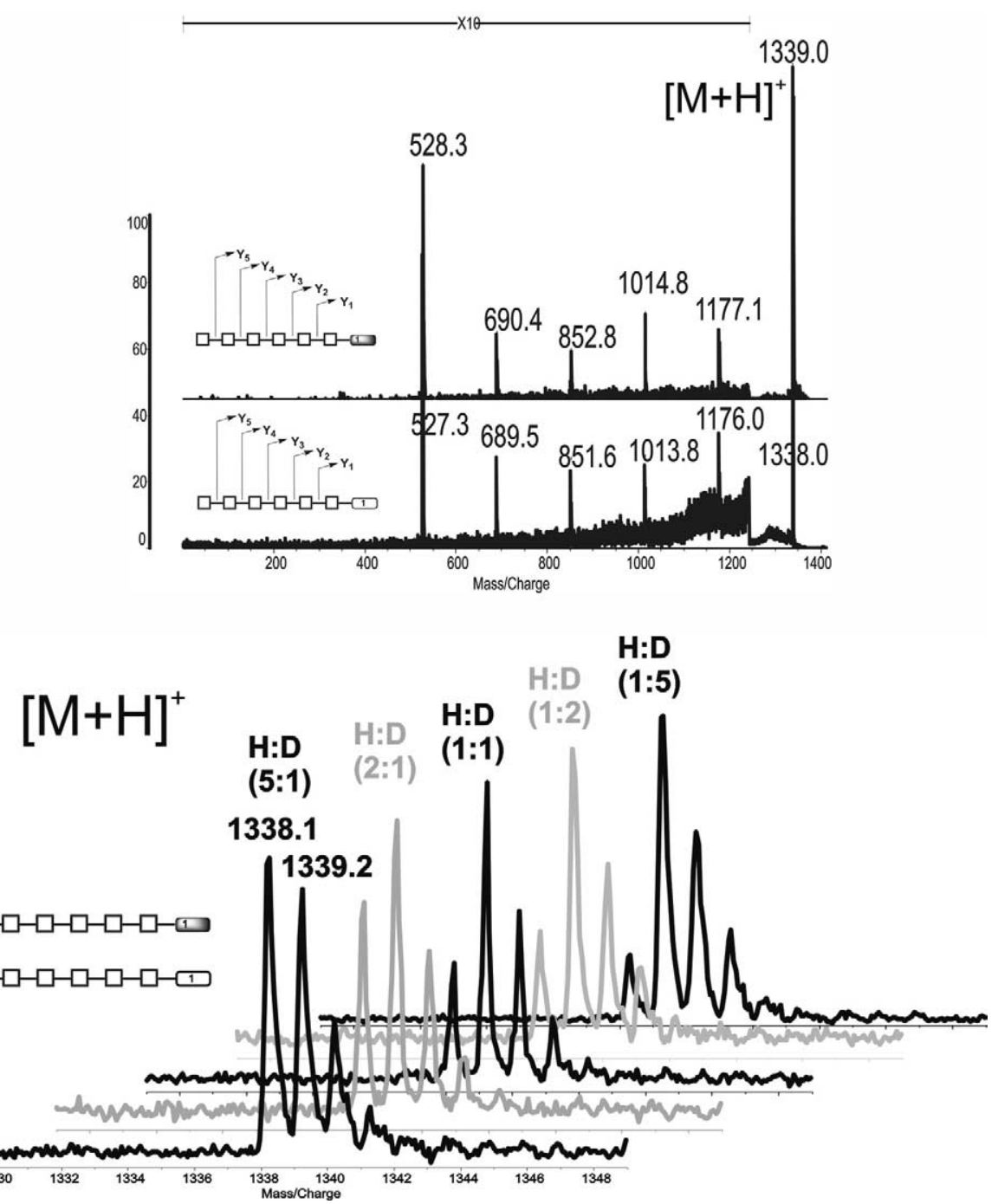

(b)

Figure 5. (a) MALDI-TOF-PSD-spectra of maltohexaose labeled with Compound 1 with and without deuterium-code. (b) Mixtures of aliquots from separately labeled maltohexaose with and without D-coding.

the same oligosaccharide was labeled both with and without deuterium-code, and different aliquots of stock solutions were applied to the MALDI-probe followed by matrix. H/D-mixtures of (5:1), (2:1), (1:1), (1:2), and (1:5) were analyzed for derivatives of maltotriose, maltohexaose, LNFP 2, and LNDFH 2. The isotope patterns of the protonated molecules $\left[\mathrm{M}+\mathrm{H}^{+}\right.$of labeled maltohexaose mixtures are shown in Figure 5b. Intensity ratios between $[\mathrm{M}+\mathrm{H}]^{+}$and $[\mathrm{M}+\mathrm{H}+1]^{+}$were determined as indicators for relative abundance of hydrogen-coded and deuterium-coded species. The observed isotope patterns were compared to the additive theoretical patterns. We found that the experimentally observed patterns were virtually identical (error $<3 \%$ ) with the theoretical patterns when three separate spectra were acquired and averaged (Table 1). Single spectra displayed errors of up to $10 \%$ from theory. However, an exact match between experimental and theoretical data

Table 1. Experimentally determined H/D-indices for various mixtures of oligosaccharides labeled with tag 1

\begin{tabular}{|c|c|c|c|c|c|c|}
\hline \multirow[b]{2}{*}{$H: D$} & \multicolumn{2}{|c|}{ Maltotriose } & \multicolumn{2}{|c|}{ Maltohexaose } & \multicolumn{2}{|c|}{ LNFP 2} \\
\hline & Theor. $\mathrm{I}_{\mathrm{M}} / \mathrm{I}_{\mathrm{M}+1}$ & Exp. $I_{M} / I_{M+1}$ & Theor. $I_{M} / I_{M+1}$ & Exp. $I_{M} / I_{M+1}$ & Theor. $\mathrm{I}_{\mathrm{M}} / \mathrm{I}_{\mathrm{M}+1}$ & Exp. $I_{M} / I_{M+1}$ \\
\hline $1: 5$ & 0.4 & 0.5 & 0.2 & 0.2 & 0.3 & 0.3 \\
\hline $1: 2$ & 0.6 & 0.8 & 0.4 & 0.4 & 0.4 & 0.5 \\
\hline $1: 1$ & 0.9 & 0.9 & 0.6 & 0.5 & 0.6 & 0.6 \\
\hline $2: 1$ & 1.2 & 1.4 & 0.9 & 0.7 & 0.9 & 0.9 \\
\hline $5: 1$ & 1.7 & 1.6 & 1.3 & 1.2 & 1.1 & 1.1 \\
\hline
\end{tabular}



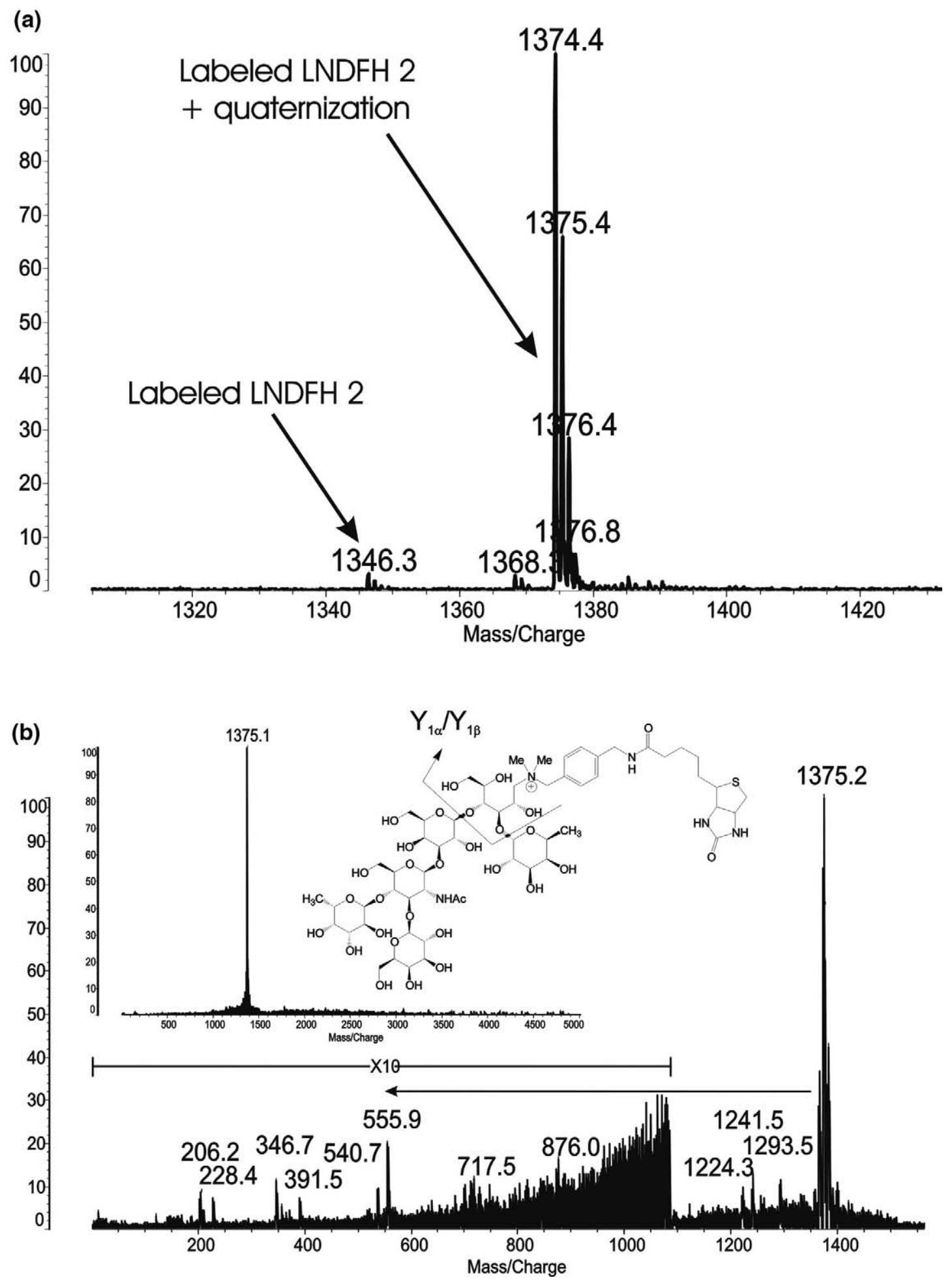

Figure 6. (a) MALDI-TOF mass spectrum of an equimolar mixture (10 nmol each) of LNDFH 2 labeled with 1 with (m/z 1374.4) and without $\mathrm{N}$-quaternization (m/z 1346.3). (b) MALDI-TOF (inset) and MALDI-TOF-PSD spectrum of N-quaternized LNDFH 2 labeled with 1 (100 fmol on probe). Although high sensitivity in detection was achieved, the MALDI-TOF-PSD-spectrum displayed reduced analytically useful fragmentation. 
(a)

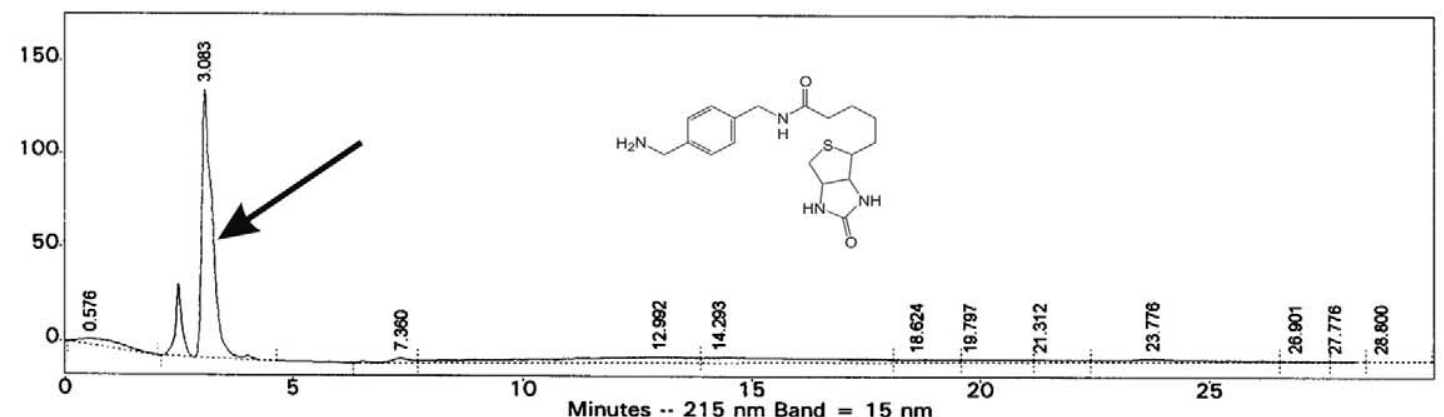

(b)

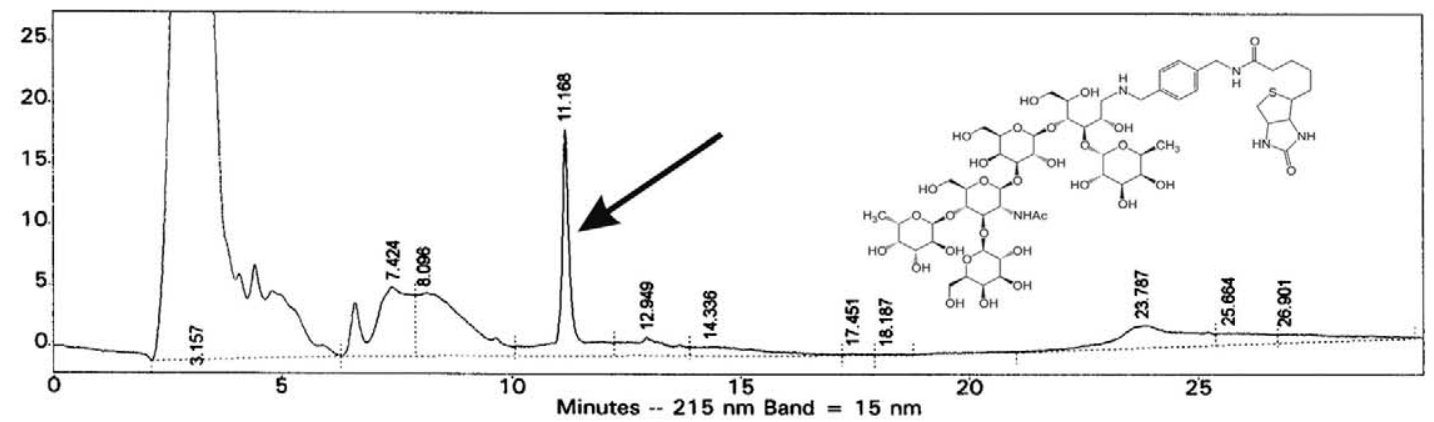

(c)

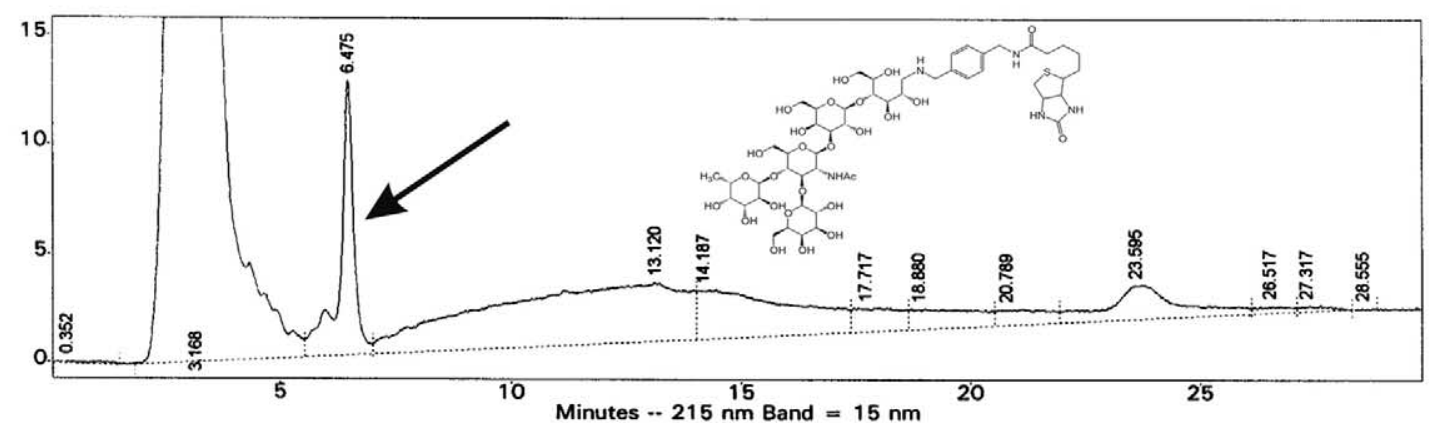

(d)
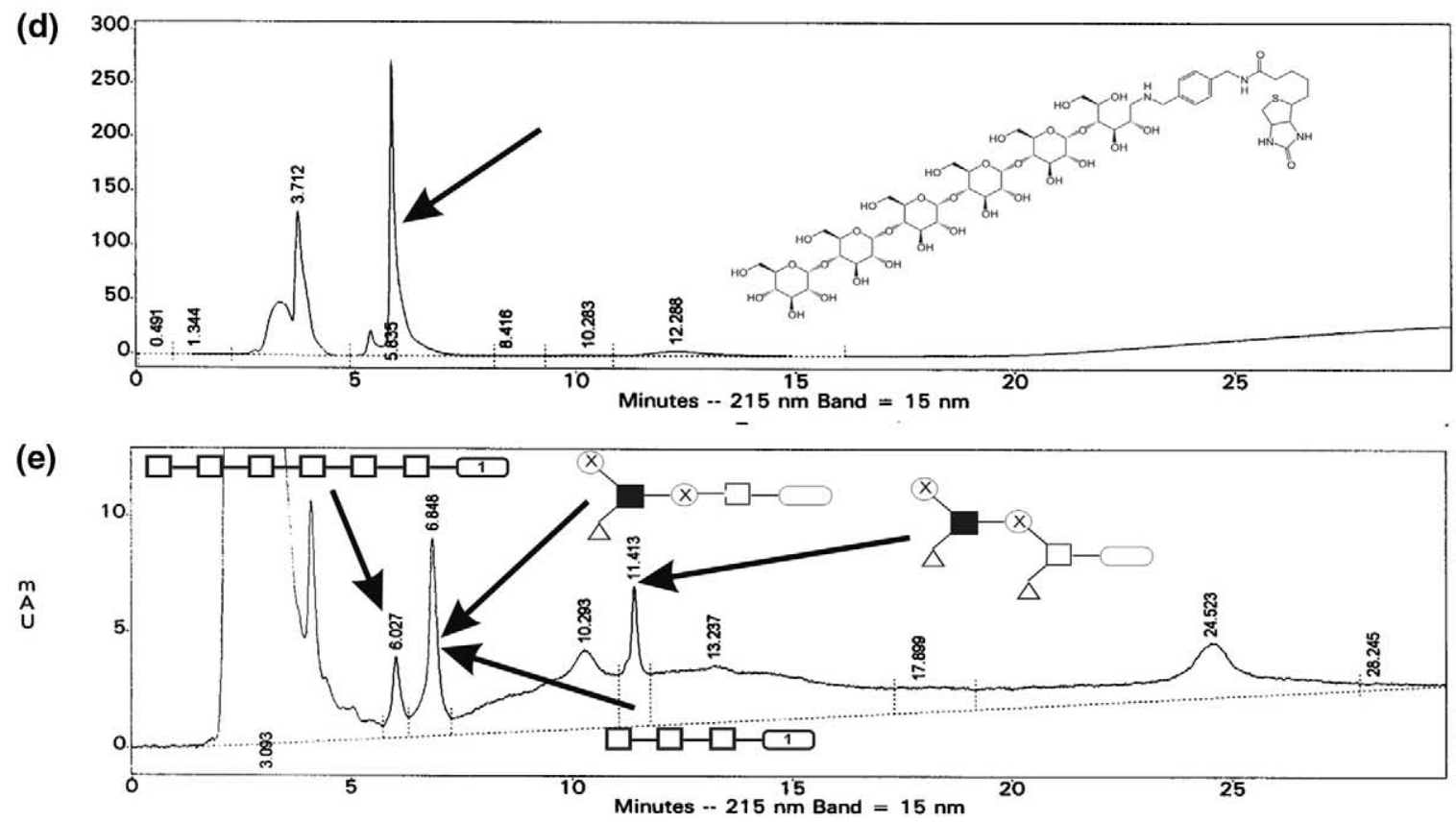

Figure 7. HPLC separation of individual labeled oligosaccharides $(\lambda=215 \mathrm{~nm})$. Solutions in $60 \%$ $\mathrm{MeCN}$ were injected unless stated otherwise; (a) $10 \mu \mathrm{L}$ injection $30 \mathrm{nmol}$ total in 50\% acetone; (b and c) $3 \mathrm{nmol}$ total; (d) $60 \mathrm{nmol}$ total and one representative mixture of labeled oligosaccharides; (e) 500 pmol total for all derivatives. The identity of the compounds was verified by off-line ESI and MALDI-TOF MS analysis. 
is not essential because the method described here yields the relative abundance of mixture components and only a consistent and reproducible reference isotope pattern is necessary.

\section{Detection Limit of Labeled Oligosaccharides}

The general detection limit of the derivatized oligosaccharides is good. A sample of 10 pmol of material applied to the MALDI-probe routinely gave a signal-tonoise ratio of better than 5:1 for the protonated molecule. However, the actual amount of material desorbed from the probe surface by the laser beam with a diameter of $\sim 5 \mu \mathrm{m}$ is significantly less. We were able to decrease the detection limit to even less material when we $\mathrm{N}$-quaternized the amino group in the labeled oligosaccharides by treatment with methyl iodide in the presence of $\mathrm{NaHCO}_{3}$ (Figure 6a). A $100 \mathrm{fmol}$ sample of $N$-quaternized LNDFH 2 applied to the MALDI-probe resulted in a signal-to-noise ratio of $>100: 1$ (Figure 6b, inset). The PSD spectrum of the ion-gate-isolated cation at $m / z 1375.1$ is shown in Figure 6b. Even at these low levels some structural information could be derived. However, we observed that the general yield of fragment ions is reduced in the case of the $N$-quaternized derivatives.

Besides an improved detection limit in mass spectrometry, N-quaternization of the labeled oligosaccharides can potentially also improve separation of labeled mixtures with capillary electrophoresis. $\mathrm{N}$-quaternization represents only one additional synthetic step, and it was found to proceed rapidly and quantitatively under mild conditions (see the Experimental section).

\section{Separation of Tagged Oligosaccharide Mixtures}

HPLC separation of tagged oligosaccharide mixtures was carried out on a $\mathrm{C}_{18}$-reverse phase column with a $\mathrm{H}_{2} \mathrm{O}-\mathrm{MeCN}$ gradient (Figure 7). The tag and several labeled derivatives of standard oligosaccharides were injected separately. We found that the tag was easily detected, and the chromatographic peaks in all cases were well-defined with narrow peak width. The identity of the compounds was confirmed by off-line MALDI-TOF MS in each case. The retention times correlated well with the overall polarity of the derivatives. Difucosylated LNDFH 2 eluted at $11.2 \mathrm{~min}$, whereas the monofucosylated LNFP 2 eluted at $6.5 \mathrm{~min}$. The tagged derivative of linear maltohexaose was detected after $5.8 \mathrm{~min}$. The separation of a mixture of labeled oligosaccharides (maltotriose, maltohexaose, LNFP 2, and LNDFH 2) was only partly successful because labeled maltotriose and labeled LNFP 2 had identical retention times. However, these two derivatives could be easily identified by their respective $\mathrm{m} / \mathrm{z}$ values in the mass spectrum. Here, we were able to demonstrate that partial HPLC separation of several tagged standard oligosaccharides is possible. Therefore, liquid chromatography of oligosaccharides labeled with the new tag can be expected to be a valuable tool in the characterization of more complicated glycan mixtures from biological sources provided the labeling efficiency is satisfactory.

\section{Conclusions}

A new multifunctional tag for oligosaccharides was synthesized and characterized. The reductive amination labeling efficiency for very small quantities of neutral oligosaccharides is high; however, higher-mass oligosaccharides appear to be labeled less efficiently. All derivatives were detected by mass spectrometry as the protonated or sodiated species with good sensitivity. Deuterium-coded derivatives were prepared, the mixtures of which, with the noncoded derivatives of the same sugar, gave characteristic isotope patterns that correlated well with the relative composition of the mixture. This method may prove useful in establishing the relative abundance of glycoprotein glycans among individuals and identification of disease markers. $\mathrm{N}$ quaternization of the derivatives resulted in a 100-fold increase in sensitivity with as little as $100 \mathrm{fmol}$ on the probe detected. It was demonstrated that the UVactivity of the tag could be used for HPLC separation studies. It has been shown that several standard oligosaccharides can be labeled successfully and that their mixtures can be separated with some limitations.

\section{Acknowledgments}

JH gratefully acknowledges financial support by an internal College of the Pacific research grant and from the Department of Chemistry. The authors express gratitude to Dionex Corporation for the donation of HPLC columns.

\section{References}

1. Hase, S. Precolumn derivatization for chromatographic and electrophoretic analyses of carbohydrates. J. Chromatogr. A 1996, 720, 173-182.

2. Harvey, D. J. Matrix-assisted laser desorption/ionization mass spectrometry of carbohydrates and glycoconjugates. Int. J. Mass Spectrom. 2003, 226, 1-35.

3. Harvey, D. J. Matrix-assisted laser desorption/ionization mass spectrometry of carbohydrates. Mass Spectrom. Rev. 1999, 18, 349-450.

4. Militsopoulou, M.; Lamari-Fotini, N.; Hjerpe, A.; Karamanos Nikos, K. Determination of twelve heparin- and heparan sulfate-derived disaccharides as 2-aminoacridone derivatives by capillary zone electrophoresis using ultraviolet and laser-induced fluorescence detection. Electrophoresis 2002, 23, 1104-1109.

5. Honda, S.; Okeda, J.; Iwanaga, H.; Kawakami, S.; Taga, A.; Suzuki, S.; Imai, K. Ultramicroanalysis of reducing carbohydrates by capillary electrophoresis with laser-induced fluorescence detection as 7-nitro2,1,3-benzoxadiazole-tagged N-methylglycamine derivatives. Anal. Biochem. 2000, 286, 99-111.

6. Okafo, G.; Langridge, J.; North, S.; Organ, A.; West, A.; Morris, M.; Camilleri, P. High-performance liquid chromatographic analysis of complex N-linked glycans derivatized with 2-aminoacridone. Anal. Chem. 1997, 69, 4985-4993.

7. Charlwood, J.; Birrell, H.; Gribble, A.; Burdes, V.; Tolson, D.; Camilleri, P. A probe for the versatile analysis and characterization of N-linked oligosaccharides. Anal. Chem. 2000, 72, 1453-1461.

8. Ahn, Y. H.; Yoo, J. S. Efficient analysis of oligosaccharide-malononitrile derivatives by on-line capillary liquid chromatography/electrospray ionization mass spectrometry. Rapid Commun. Mass Spectrom. 1999, 13, $855-859$.

9. Lemoine, J.; Cabanes-Macheteau, M.; Bardor, M.; Michalski, J.-C.; Faye, L.; Lerouge, P. Analysis of 8-aminonaphthalene-1,3,6-trisulfonic acid labeled N-glycans by matrix-assisted laser desorption/ionization time- 
of-flight mass spectrometry. Rapid Commun. Mass Spectrom. 2000, 14, $100-104$.

10. Suzuki, H.; Mueller, O.; Guttman, A.; Karger, B. L. Analysis of 1-aminopyrene-3,6,8-trisulfonate-derivatized oligosaccharides by capillary electrophoresis with matrix-assisted laser desorption/ionization timeof-flight mass spectrometry. Anal. Chem. 1997, 69, 4554-4559.

11. Turecek, F. Mass spectrometry in coupling with affinity capture-release and isotope-coded affinity tags for quantitative protein analysis. J. Mass Spectrom. 2002, 37, 1-14.

12. Patton, W. F.; Schulenberg, B.; Steinberg, T. H. Two-dimensional gel electrophoresis; better than a poke in the ICAT? Curr. Opin. Biotechnol. 2002, 13, 321-328

13. Patton, W. F. Detection technologies in proteome analysis. Analytical technologies in the biomedical and life sciences. J. Chromatogr. B 2002, $771,3-31$.

14. Mo, W.; Sakamoto, H.; Nishikawa, A.; Kagi, N.; Langridge, J. I.; Shimonishi, Y.; Takao, T. Structural characterization of chemically derivatized oligosaccharides by nanoflow electrospray ionization mass spectrometry. Anal. Chem. 1999, 71, 4100-4106.

15. Harvey, D. J. Collision-induced fragmentation of underivatized Nlinked carbohydrates ionized by electrospray. J. Mass Spectrom. 2000, 35, 1178-1190.

16. Zeleny, R.; Altmann, F.; Praznik, W. Structural characterization of the N-linked oligosaccharides from tomato fruit. Phytochemistry 1999, 51, 199-210.

17. Mechref, Y.; Novotny, M. V. Structural investigations of glycoconjugates at high sensitivity. Chem. Rev. 2002, 102, 321-369.

18. Kennedy, R. T.; German, I.; Thompson, J. E.; Witowski, S. R. Fast analytical-scale separations by capillary electrophoresis and liquid chromatography. Chem. Rev. 1999, 99, 3081-3131.

19. Rothenberg, B. E.; Hayes, B. K.; Toomre, D.; Manzi, A. E.; Varki, A. Biotinylated diaminopyridine: An approach to tagging oligosaccharides and exploring their biology. Proceedings of the National Academy of Sciences of the United States of America; 1993; pp 11939-11943.

20. Toomre, D. K.; Varki, A. Advances in the use of biotinylated diaminopyridine (BAP) as a versatile fluorescent tag for oligosaccharides. Glycobiology 1994, 4, 653-663.

21. Varki, A.; Rothenberg, B. E. Novel Fluorescent Tagging Agents, Patent Corporation Treaty (PCT) International Property Organization, World Intellectual Property Organization, 1994, pp 38.

22. Shinohara, Y.; Sota, H.; Gotoh, M.; Hasebe, M.; Tosu, M.; Nakao, J.; Hasegawa, Y.; Shiga, M. Bifunctional labeling reagent for oligosaccha- rides to incorporate both chromophore and biotin groups. Anal. Chem. 1996, 68, 2573-2579.

23. Love, K. R.; Seeberger, P. H.Carbohydrate arrays as tools for glycomics. Angew. Chem. Int. Ed. 2002, 41, 3583-3586

24. Leteux, C.; Childs, R. A.; Chai, W.; Stoll, M. S.; Kogelberg, H.; Feizi, T. Biotinyl-L-3-(2-naphthyl)-alanine hydrazide derivatives of N-glycans: Versatile solid-phase probes for carbohydrate-recognition studies. Glycobiology 1998, 8, 227-236.

25. Broberg, S.; Broberg, A.; Duus, J. O. Matrix-assisted laser desorption/ ionization time-of-flight mass spectrometry of oligosaccharides derivatized by reductive amination and $\mathrm{N}, \mathrm{N}$-dimethylation. Rapid Commun. Mass Spectrom. 2000, 14, 1801-1805.

26. An, H. J.; Franz, A. H.; Lebrilla, C. B. Improved capillary electrophoretic separation and mass spectrometric detection of oligosaccharides. J. Chromatogr. A 2003, 1004, 121-129.

27. Domon, B.; Costello, C. E. A systematic nomenclature for carbohydrate fragmentations in FAB-MS/MS spectra of glycoconjugates. Glycoconj. J. 1988, 5, 397-409.

28. Garlick, R. K.; Giese, R. W. Avidin binding of radiolabeled biotin derivatives. J. Biol. Chem. 1988, 263, 210-215

29. Plummer, T. H., Jr.; Elder, J. H.; Alexander, S.; Phelan, A. W.; Tarentino, A. L. Demonstration of peptide:N-glycosidase F activity in endo-b-Nacetylglucosaminidase F preparations. J. Biol. Chem. 1984, 259, 1070010704.

30. An, H. J.; Peavy, T. R.; Hedrick, J. L.; Lebrilla, C. B. Determination of $\mathrm{N}$-glycosylation sites and site heterogeneity in glycoproteins. Anal. Chem. 2003, 75, 5628-5637.

31. Plummer, T. H., Jr.; Tarentino, A.; Maley, F. The glycopeptide linkage of ribonuclease B. J. Biol. Chem. 1968, 243, 5158-5164.

32. Bahl, O. P.; Agrawal, K. M. L. Glycosidases of Phaseolus vulgaris. I. Isolation and characterization of $\mathrm{b}-\mathrm{N}$-acetylglucosaminidase. J. Biol. Chem. 1968, 243, 98-102.

33. Tarentino, A. L.; Plummer, T. H., Jr.; Maley, F. Release of intact oligosaccharides from specific glycoproteins by endo-b-N-acetylglucosaminidase H. J. Biol. Chem. 1974, 249, 818-824.

34. Takahashi, N. Demonstration of a new amidase acting on glycopeptides. Biochem. Biophys. Res. Commun. 1977, 76, 1194-1201.

35. Takahashi, N.; Nishibe, H. Some characteristics of a new glycopeptidase acting on aspartylglycosylamine linkages. J. Biochem. Tokyo, Japan 1978, 84, 1467-1473. 